\title{
Racial Disparities in Neighborhood Arrest Rates during the COVID-19 Pandemic
}

\author{
Jaquelyn L. Jahn ${ }^{(D)}$ Jessica T. Simes • \\ Tori L. Cowger $\cdot$ Brigette A. Davis
}

Accepted: 1 December 2021 / Published online: 11 January 2022

(C) The New York Academy of Medicine 2022

\begin{abstract}
Structural racism in police contact is an important driver of health inequities among the U.S. urban population. Hyper-policing and police violence in marginalized communities have risen to the top of the national policy agenda, particularly since protests in 2020. How did pandemic conditions impact policing? We assess neighborhood racial disparities in arrests after COVID-19 stay-at-home orders in Boston, Charleston, Pittsburgh, and San Francisco census
\end{abstract}

Jaquelyn L. Jahn and Jessica T. Simes share first authorship.

Supplementary Information The online version contains supplementary material available at https://doi. org/10.1007/s11524-021-00598-z.

J. L. Jahn $(\bowtie)$

The Ubuntu Center On Racism, Global Movements, and Population Health Equity, Drexel University Dornsife School of Public Health, Philadelphia, PA, USA

e-mail: jackie.jahn@drexel.edu

J. T. Simes

Department of Sociology, Boston University, Boston, MA, USA

T. L. Cowger

Department of Epidemiology, Harvard T.H. Chan School of Public Health, Boston, MA, USA

B. A. Davis

Department of Obstetrics \& Gynecology and the California Preterm Birth Initiative, University of California San Francisco, San Francisco, CA, USA tracts (January 2019-August 2020). Using interrupted time series models with census tract fixed effects, we report arrest rates across tract racial and ethnic compositions. In the weeks following stay-at-home orders, overall arrest rates were 39\% lower (95\% CI: $37-41 \%)$ on average compared to rates the year prior. Although arrest rates steadily increased thereafter, most tracts did not reach pre-pandemic arrest levels. However, despite declines in nearly all census tracts, the magnitude of racial inequities in arrests remained unchanged. During the initial weeks of the pandemic, arrest rates declined significantly in areas with higher Black populations, but average rates in Black neighborhoods remained higher than pre-pandemic arrest rates in White neighborhoods. These findings support urban policy reforms that reconsider police capacity and presence, particularly as a mechanism for enforcing public health ordinances and reducing racial disparities.

Keywords Structural racism - COVID-19 . Policing $\cdot$ Racial disparity $\cdot$ Neighborhoods

\section{Introduction}

As cities across the country aimed to stem the spread of SARS-CoV-2 through stay-at-home orders beginning in March 2020, municipalities tasked police officers with the enforcement of local ordinances such as curfews, mandatory mask wearing, and reduced 
crowd size [1]. Police deployed checkpoints and electronic monitoring and stopped and arrested people to enforce social distancing guidelines [2, 3]. Residents in many cities were encouraged to report suspected violations of distancing guidelines to law enforcement [4]. Just a few months into the pandemic, protests over racist police killings of Black Americans erupted across the country, calling for systemic change in policing. In a pandemic responsible for the deaths of over 800,000 Americans by the close of 2021, these conditions of policing point to the expansive role of law enforcement in addressing health emergencies and the urgent need for evaluating police practices in marginalized neighborhoods [5].

Policing is ubiquitous in American life: in an average year, police make approximately 50,000 stops per day and over 10 million arrests per year [6, 7]. Among all young adults born in the early 1980s, about $30-41 \%$ will be arrested at least once by age 22 [8]. Research has documented substantial disparities in arrests across neighborhood racial and ethnic composition, analyzing racially unequal policing practices as a form of structural racism that contributes to racial health inequities [9-11]. Research on the degree of police contact in Black neighborhoods describes a landscape of "divergent social worlds," where Black communities experience such extreme levels of police contact that there are not enough White neighborhoods to draw relevant comparisons [10, 12]. A large research literature has examined neighborhood context and racial disparities in arrests, finding that after accounting for socioeconomic and other neighborhood-level factors, substantial residual arrest differences between Black and White populations remain, explained largely by inequitable enforcement practices [9, 13-16].

High and racially unequal rates of police encounters have significant implications for population health and racial health equity. Frequent police contact is associated with higher levels of anxiety and psychological distress, especially when interactions are understood to be unfair or discriminatory [17, 18]. Those living in chronically policed neighborhoods are more likely to have severe feelings of nervousness and worthlessness, particularly among young men [19]. Fatal police encounters are a major cause of death among Black men [20], and these incidents also likely have "spillover" effects for residents of surrounding areas [21,22]. Recent calls for police reform and defunding police departments following the police killings of Breonna Taylor and George Floyd emerged in response to persistent, racially inequitable patterns of policing in Black communities, in addition to a growing concern that police contact during the pandemic was occurring disproportionately in communities of color [3, 23].

Police contact poses increased threats to public health under pandemic conditions. Stops, searches, and arrests involve close physical contact, and in most cases, searches and arrests involved sustained close physical contact between the person being searched and police officers [24]. After arrest, people may be processed indoors and placed in cells with others, or eventually incarcerated in jail, where conditions promote the spread of SARS-CoV-2 among incarcerated individuals, staff, and surrounding communities [24-27]. Moreover, avoidance of aggressive police encounters in heavily policed neighborhoods could potentially worsen the psychological strain of social distancing protocols. Coupled with the evidence that COVID-19 case and death rates have been highest among people of color, the pandemic has potentially impacted marginalized urban populations in multiple ways [28, 29].

The COVID-19 pandemic provides a novel opportunity to study how police practices may have shifted in response to stay-at-home mandates, and under these conditions, how disparities in policing across urban neighborhoods either widened or narrowed. Only one prior study has examined changes to U.S. police practice during the COVID-19 pandemic [1], though more research has focused on changes to reported crime during the 2020 pandemic [30]. Using a geo-identified dataset of arrests from four major U.S. cities, we study arrests across census tracts of different racial and ethnic compositions to examine how policing may have shifted in the context of stayat-home orders and social distancing enforcement. Our research questions are thus twofold: did arrests rates change in the six months after the implementation of stay-at-home orders in urban cities? Second, did neighborhood racial and ethnic disparities in arrest rates shift during stay orders? How police presence may have shifted during the pandemic will be informative of how neighborhood disparities in police contact remain or change under health crisis conditions, and how these changes speak to baseline racial 
disparities in arrests that reproduce structural racism in American communities.

\section{Materials and Methods}

Data

We used police administrative data from four cities representing different regions with geographic data on arrests from January 2019 to August 2020. The Boston Police Department provided researchers with arrest data upon request, but data from other cities is publicly available. For the analysis, we examined geocoded arrest data from Boston, Charleston, Pittsburgh, and San Francisco, which all enacted stay orders during March 2020. These cities were selected based on arrest data availability for the 2019-2020 period, their racial and ethnic diversity, and the desire to include multiple regions of the U.S. as stay orders unfolded. Stay orders varied across local and state jurisdictions, but we determined stay order dates using a combination of local news reports and press releases from state and local governments covering each of the four cities. Cities slightly varied in terms of the timing of the stay order, ranging from March 19, 2020, in California, to April 7, 2020, in South Carolina. We account for the timing of stay orders in our modeling strategy. While there was variation in the rules and stipulations pertaining to stay orders, three main conditions were upheld in all four cities: the closure of non-essential businesses, the closure of all public schools, and the prohibition on public gatherings.

Data for this period include the latitude/longitude and date of each incident, which we aggregated to the census tract-week level. We geocoded the XY arrest data to census tracts for each of the four cities and linked these data to census data from the American Community Survey 5-Year Estimates (2015-2019), which provided data on tract population and racial/ ethnic composition. We analyze arrest data for 525 census tracts observed across 87 weeks.

In addition to total arrests, we coded several arrest categories following Uniform Crime Reports definitions (e.g., violent, property, and drug-related). We also created a distinct category combining arrests for gatherings or public disturbances (e.g., loitering, trespassing), which may be related to enforcing social distancing during the pandemic. Arrests for gatherings, drugs, and property involve the greatest levels of police discretion compared to arrests for violence. We include in Supplemental Table 1 descriptive statistics of arrest types that form the dependent variables for the analysis.

\section{Statistical Analysis}

To estimate the temporal change in rates of police contact, we implemented interrupted time series (ITS) negative binomial regression models with an offset for the log census tract population [31]. We estimated changes in the average rates of arrest, comparing the year prior to stay-at-home orders to the 24 weeks following the stay order (March 2020-August 2020) and express these in terms of percentage change for ease of interpretation.

Our dependent variables include all arrests, and arrests for violent, property, drug, and gathering offenses, each examined in separate models. Models include a census tract fixed effect to account for timeinvariant confounders and a month fixed effect to account for seasonality. To assess whether time trends in arrests were consistent across census tract racial composition, we first estimated models stratified by quintiles of census tract racial/ethnic composition. Quintiles are estimated within cities, as racial composition varies greatly by city context. We chose to use quintiles as opposed to a specific cutoff of racial/ethnic composition (e.g., $>60 \%$ White, Black, Hispanic, or Asian) due to differences in city racial compositions and the sample size of neighborhoods for each racial composition. Secondly, we estimate changes in the relative racial inequity in arrests before, immediately following, and after stay-at-home orders in a model that interacted racial composition quintile with our variable for weeks since January 2019 and an indicator for pre/post-stay-at-home order [31].

\section{Sensitivity Analysis}

We conducted three sensitivity analyses to test the robustness of our findings. First, we implemented two additional temporal comparisons to understand changes in rates of arrest post-stay-at-home orders. In Supplemental Fig. 2, we present rate ratios of arrests post-stay order as compared to (1) the on-average level of arrests for the 24 weeks prior (October 
2019-March 2020) and (2) the average level of arrests during the same weeks in the year 2019. Our second sensitivity analysis implemented an alternative modeling strategy to assess temporal variation on a week-to-week scale, relative to arrests on average in the year prior. Our third sensitivity analysis assesses week-to-week changes in arrests separately for each city, to examine whether our on-average findings held across place and after the police killing of George Floyd and subsequent large-scale urban protests.

\section{Results}

In the 24 weeks after stay-at-home orders went into effect, average weekly arrest rates decreased from 52.73 to 32.49 arrests per 100,000 populations. Our models suggest that weekly arrests declined by 39\% (CI: $37-41 \%$ ) within census tracts relative to the year prior and after adjustment for seasonality
(Supplemental Table 1). These declines were observed in all included cities (Supplemental Fig. 1). Rates of arrest decreased across all different arrest types (Fig. 1). Compared to the year before stay orders were implemented, weekly arrests for violencerelated offenses decreased by 35\% (CI: 32-39\%) on average following stay orders. Weekly propertyrelated arrests decreased by $21 \%$ (CI: 16-26\%), and arrests for gatherings and other public disorder offenses, in a context of social distancing enforcement, decreased by $45 \%$ (CI: 40-49\%) compared with average rates in the year prior. We observed the most dramatic decreases in weekly drug arrests, which dropped from 9.17 per 100,000 population in 2019 to 3.32 after stay orders, a relative decline of $54 \%$ (CI: 50-58\%) after adjustment for seasonality. All these results are statistically significant at conventional levels $(p<0.001)$. However, as Fig. 1 shows, after the first 9 weeks, most types of arrest begin to increase to similar levels compared to the year pre-stay order,

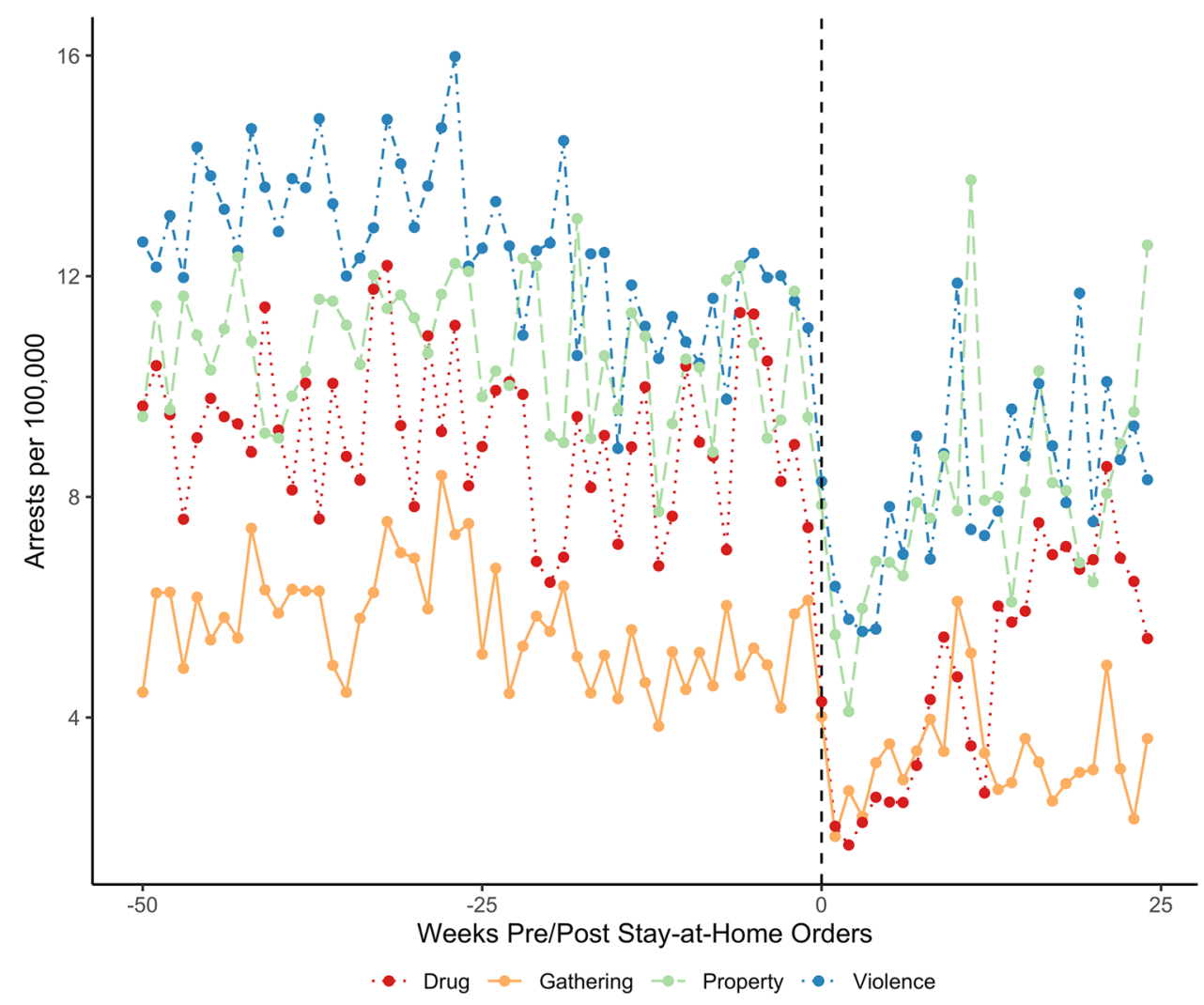

Fig. 1 Time trends in types of arrest before and 24 weeks after stay-at-home orders. Census tract rates of drug, gathering, property, and violence arrests in Boston, Charleston, San Francisco, and Pittsburgh for each week from January 2019 to August 2020 
though still lower on average. Arrests in Charleston in particular returned to 2019-levels before the other three cities (Supplemental Fig. 1).

Next, we assessed whether these decreases in arrest rates were consistent across census tract racial and ethnic composition. Arrest rates in tracts with the highest proportion of Black residents (Q5) dropped from 85.18 per 100,000 populations in the year prior to 52.06 after stay orders, and areas with the lowest proportion of Black residents (Q1) changed from 22.56 to 14.76 per 100,000 populations. Figure 2 plots total arrests by the top quintile (80th percentile within each city) of non-Hispanic White, nonHispanic Black, non-Hispanic Asian, and Hispanic or Latino census tract population, and shows initial declines in weekly rates of arrest but persistently elevated rates among neighborhoods with the highest proportion of Black and Hispanic residents, relative to more White and Asian neighborhoods. We find that arrest rates were significantly decreased in the 24 weeks after stay orders in all models stratified by racial/ethnic composition compared to rates in 2019 on average (Fig. 3 and Supplemental Table 1). Negative decreases in arrest rates were statistically significant in all racial compositions and nearly all arrest types $(p<0.001$, Supplemental Table 1). Except for property crime in the top quintile of White population, weekly rates of arrest for violence, drugs, property, and gatherings all significantly declined after stay orders compared with the year prior in areas containing the top quintile of Black, Latino, and Asian population (Fig. 3). Given significant anti-Asian hate crimes and the possibility that anti-Asian discrimination rose among police and citizens during the pandemic [32], we highlight results in Fig. 3 that suggest census tracts with the top quintile of Asian population had less sharp declines in gathering arrests after stay orders, relative to changes in other areas.

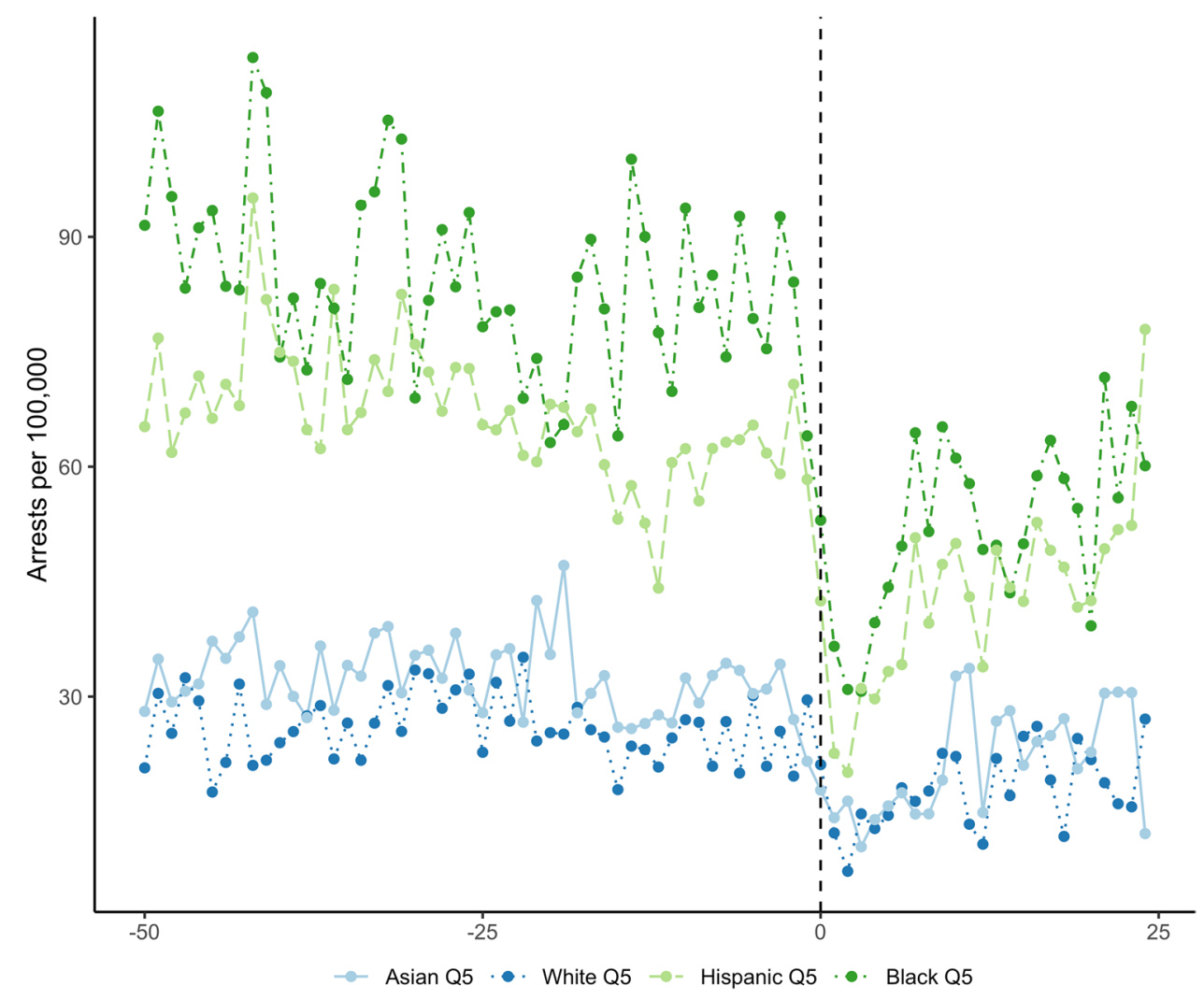

Fig. 2 Time trends in rates of arrest before and 24 weeks after stay at home orders, stratified by census tract racial composition. Rates of arrests in census tracts with the highest quintiles of Asian, White, Hispanic, and Black populations in Boston, Charleston, San Francisco, and Pittsburgh for each week from January 2019 to August 2020 


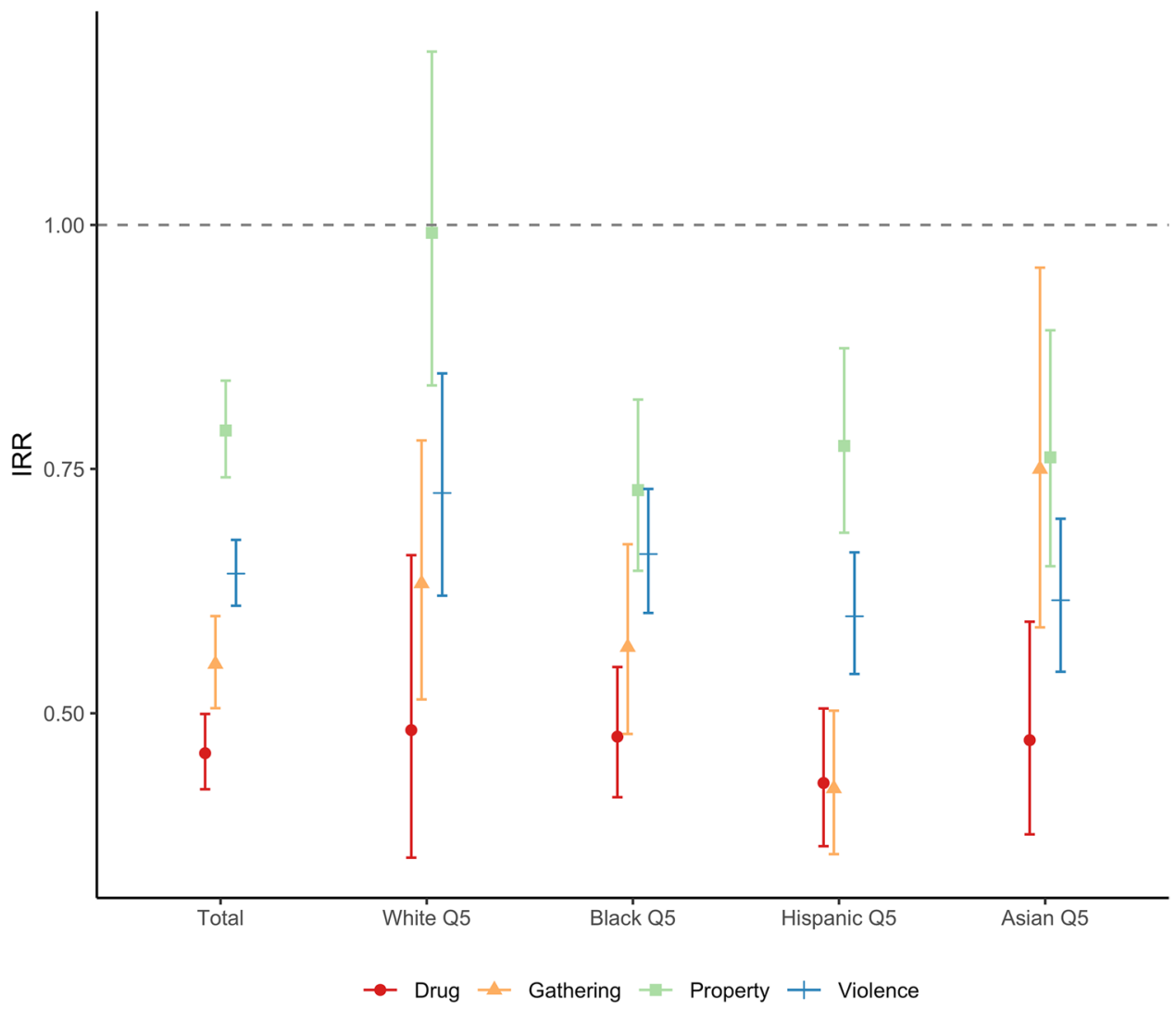

Fig. 3 Changes in arrests after stay-at-home orders compared with arrests in 2019, stratified by arrest type and racial/ethnic composition. Incidence rate ratios (IRRs) and 95\% confidence intervals estimating changes in census tract rates of drug, gath-

We additionally explored temporal variation in the disparity in arrests across neighborhood racial composition both immediately following as well as in the 24 weeks after stay orders as compared with average rates in the year prior. These models interact neighborhood racial composition variables with our temporal indicators, and a value different from 1 indicates a change in the racial disparity. Despite overall declines in arrest rates shown in Figs. 1 and 2, we find that there is no immediate or sustained change in the relative disparity in weekly arrests across neighborhood racial composition as compared with the average disparity in 2019. For example, the racial disparity in arrests comparing neighborhoods with the highest to lowest proportion of Black residents did not change immediately following stay orders compared to the disparity in the year prior (IRR: $0.87,95 \% \mathrm{CI}$ : 0.31-2.47). There was also no significant change in ering, property, and violent arrests after stay-at-home orders as compared with the year prior (2019). Negative binomial models are stratified by quintiles of racial/ethnic composition and include census tract and month fixed effects

this disparity after stay orders compared with 2019 (IRR: 1.00, 95\% CI: 0.99, 1.01). Indeed, average arrest rates in Black neighborhoods after stay-athome orders barely approach pre-pandemic rates in White communities (Fig. 2).

The objective of our sensitivity analyses was to test whether the declines in arrests we observed in the 24 weeks following stay orders compared to 2019 on average held when using different temporal comparisons. We first compared only the 24 weeks before versus after the stay order to isolate an effect of the stay order more closely. We find that a similar reduction in weekly arrests using this temporal comparison as with the comparison to 2019 on average in our main analysis (Supplemental Fig. 2). Next, as an alternative seasonality control, we compared weekly arrest rates in the 24 weeks after stay orders to the on-average levels of arrest for those same weeks in 2019, and we 
find similar results to our main analysis (Supplemental Fig. 2).

Lastly, we examined temporal variation on a weekto-week scale using indicators to separately compare every week after the stay order to arrests in 2019 on average. These models allow us to separate initial declines immediately following the stay order from potential rises in later weeks. These more granular models show that arrests declined most sharply initially but that decreases in the later weeks were still lower in comparison to rates in 2019 on average (Supplemental Fig. 3). We also used these more granular temporal models to study cities separately and observed that arrests initially declined everywhere, but in Charleston rates rose to levels not significantly different from 2019 by 7 weeks after stayat-home orders. Similarly, in Pittsburgh, by 17 weeks after stay orders, weekly arrest rates were no longer significantly different from the year prior (Supplemental Fig. 4). Moreover, arrests in Charleston, San Francisco, and Boston temporarily rose to 2019 levels for the weeks after the police killing of George Floyd, though it cannot be distinguished from a rise in arrests that preceded his death (Supplemental Fig. 4).

\section{Discussion}

We investigated the impact of stay-at-home orders on police arrests in four U.S. cities for the first six months of the COVID-19 pandemic. We found that arrests of all types declined dramatically in all four cities-especially in the initial weeks of the stay order and gradually rose towards but remained on average lower than 2019 levels. We interpret this finding as resulting from both the conditions of social distancing and changes to police activity. Police could have made fewer arrests because fewer people were outdoors and engaging in public activities, and in Charleston, for example, police were instructed to scale back on in-person responding to certain nonviolent complaints [33]. On the other hand, in San Francisco and elsewhere across the country, police were instructed to enforce public health ordinances $[2,34]$. However, all cities temporarily returned to 2019 arrest rates at some point after stay-at-home orders, and arrest rates rebounded earlier in Charleston compared to other cities.
Although declines in arrests were experienced in Black, White, Latino, and Asian neighborhoods, racial inequities in arrests persisted. Our results reveal profound racial inequities in arrests in neighborhoods prior to the pandemic that persisted into a period of significant social change. Arrest rates declined significantly in areas with higher Black populations, but average rates in Black neighborhoods remained higher than the pre-pandemic arrest rates in White communities. During a pandemic, the shutting down of major cities, and social movements calling for systemic change in policing, cities had a unique opportunity to address racial inequities in policing. Our results demonstrate that under these conditions and a dramatic decline in overall arrest rates, the racialspatial divide in police contact persists in these four U.S. cities.

These findings demonstrate the importance of analyzing multiple comparison groups to illuminate both overall and relative differences across neighborhood racial/ethnic composition. In the case of the COVID-19 pandemic, this would include comparing post-stay-order levels to pre-pandemic levels of arrest within Black and Latino neighborhoods, say, as well as comparing those rates to baseline and post-trends in White neighborhoods. Considering the first comparison, we saw the effect of the pandemic for arrests is strongest in areas that were chronically policed prior to the implementation of stay orders. These intense declines in arrest within Black neighborhoods suggest conditions of excessive policing in those places, especially given the decreases were largest for arrest types involving the greatest discretion (e.g., drugs and public disorder). Despite these precipitous declines in arrests, racial disparities in comparison to White neighborhoods remained unchanged. Thus, in a study of policing during a period of significant social change, our findings demonstrate the persistence of structural racism in arrest rates in urban neighborhoods.

Arrests are the front door to the larger criminal legal system, and we find in the six months following stay-at-home orders, police made significantly fewer arrests in all neighborhoods compared to earlier months. In short, the pandemic forced rapid change and reduction in entry to the criminal justice system [35]. Courts shut down, resulting in a dramatic decline in fines, bail, and incarceration for pre-trial detention [36]. Although incarcerated populations 
declined in some jurisdictions, prisons, jails, and detention centers substantially contributed to the spread of infection and preventable deaths among incarcerated people and staff $[25,27,37]$. The crisis conditions of a lethal infectious disease called into question the public health provision, safety, and ethical status of criminal justice institutions. When the pandemic is over, these public health and ethical questions will remain $[23,38]$. The current study proposes a reevaluation of the original levels of policing prior to stay orders and a deep examination of the persistence of racial disparity in exposure to criminal justice contact in urban communities. Our analysis examines policing as an important site for criminal justice contact that has consequences for urban health and health equity.

This study also has limitations that should be noted. First, results may not be generalizable to cities beyond those examined in this study, especially as the pandemic unfolded unevenly across localities. However, these cities are demographically and socioeconomically diverse, particularly in terms of their share of White and Black populations. Future analyses could extend the study of neighborhood racial/ethnic composition to include measures of neighborhood change such as gentrification, and incorporate individual-level race/ethnicity data, which could allow for tests of interactions between individual and contextual factors that might prove significant for explaining arrest risk during the pandemic. A second limitation is that arrests are only a subset of police encounters, and thus, our data underestimate the role of police contact during the pandemic. One study in New York City suggests that criminal court summonses were used to enforce COVID-19 policies [1]. Additional public monitoring of arrests and other police encounters could be part of a broad strategy for improved oversight of police through consistent data standards. Additionally, we cannot account for changes in the underlying behavior in the population, as this cannot be observed with available public data. Declines in arrests are likely due to both changes in policing practices as well as changes in criminalized behaviors in the context of social and economic change resulting from the pandemic. An analysis of social distancing enforcement in New York City found that racial inequities in pandemic-related arrests and summonses persisted even after adjustment for mobility patterns in the population and pointed to other factors shaping arrest patterns besides movement outside of the home [1].

This study established the first estimates of urban neighborhood rates of arrest during the COVID-19 pandemic. As police contact is a mechanism of urban health disparities, our findings suggest that public health interventions should focus on the harmful consequences of policing to administer public health ordinances, and that resources for encouraging compliance could be usefully directed away from police and towards non-punitive institutions and practitioners. Police contact has health harms that predate COVID-19 [17, 18], and during the pandemic, police contact may have contributed to community transmission of the virus through jail incarceration [25, 26].

Moreover, as vaccinations and re-openings point to shifts back to a semblance of community life prior to the pandemic, public health responses to interpersonal and gun violence, drug use, and other criminalized behaviors could be an important shift that avoids returning to pre-pandemic policing levels. Indeed, non-punitive public health approaches could meaningfully reduce the role of police in ensuring the well-being of marginalized communities [37], and investing in community-based alternatives promoting public health is integral to addressing the persistent high levels of criminal justice contact before, during, and after the pandemic stay orders observed in this study.

Acknowledgements This research was funded by the Social Science Research Council, the Scholars Strategy Network, and the Boston University Initiative on Cities.

\section{References}

1. Kajeepeta S, Bruzelius E, Ho JZ, Prins SJ. Policing the pandemic: estimating spatial and racialized inequities in New York City police enforcement of COVID-19 mandates. Crit Public Health. 2021; 1-12. https://doi.org/10. 1080/09581596.2021.1987387.

2. Marshall BDL, Shihipar A. Opinion I We can't police our way out of a pandemic. The New York Times. https://www. nytimes.com/2020/04/27/opinion/coronavirus-police. html. Published April 27, 2020. Accessed March 9, 2021.

3. Grant MG. The pandemic is the right time to defund the police. The New Republic. Published online May 28, 2020. Accessed March 9, 2021. https://newrepublic.com/ article/157875/pandemic-right-time-defund-police.

4. Kallingal M. Ankle monitors ordered for Louisville, Kentucky residents exposed to Covid-19 who refuse to 
stay home. CNN. Accessed March 9, 2021. https://www. cnn.com/2020/04/03/us/kentucky-coronavirus-residentsankle-monitors-trnd/index.html.

5. Laufs J, Waseem Z. Policing in pandemics: a systematic review and best practices for police response to COVID19. Int J Disaster Risk Reduct. 2020;51: 101812. https:// doi.org/10.1016/j.ijdrr.2020.101812.

6. The Stanford Open Policing Project. openpolicing.stanford.edu. Accessed March 9, 2021. https://openpolicing. stanford.edu/.

7. Crime in the United States 2019. US Department of Justice Federal Bureau of Investigation. Accessed March 9, 2021. https://ucr.fbi.gov/crime-in-the-u.s/2019/crime-inthe-u.s.-2019/topic-pages/persons-arrested.

8. Brame R, Turner MG, Paternoster R, Bushway SD. Cumulative prevalence of arrest from ages 8 to 23 in a national sample. Pediatrics. 2012;129(1):21-7. https://doi. org/10.1542/peds.2010-3710.

9. Kirk DS. The neighborhood context of racial and ethnic disparities in arrest. Demography. 2008;45(1):55-77. https://doi.org/10.1353/dem.2008.0011.

10. Peterson RD, Krivo LJ. Divergent social worlds: neighborhood crime and the racial-spatial divide. Russell Sage Foundation; 2010. Accessed March 9, 2021. https://www. russellsage.org/publications/divergent-social-worlds-0.

11. Bailey ZD, Krieger N, Agénor M, Graves J, Linos N, Bassett MT. Structural racism and health inequities in the USA: evidence and interventions. Lancet. 2017;389(10077):1453-63. https://doi.org/10.1016/ S0140-6736(17)30569-X.

12. Sampson RJ. Moving to inequality: neighborhood effects and experiments meet social structure. Am J Sociol. 2008;114(1):189-231. https://doi.org/10.1086/589843.

13. Gaston S. Enforcing race: a neighborhood-level explanation of Black-White differences in drug arrests. Crime Delinq. 2019;65(4):499-526. https://doi.org/10.1177/ 0011128718798566.

14. Gaston S. Producing race disparities: a study of drug arrests across place and race*. Criminology. 2019;57(3):424-51. https://doi.org/10.1111/1745-9125. 12207.

15. Donnelly EA, Wagner J, Stenger M, Cortina HG, O'Connell DJ, Anderson TL. Opioids, race, and drug enforcement: exploring local relationships between neighborhood context and Black-White opioid-related possession arrests. Crim Justice Policy Rev. 2021;32(3):219-44. https://doi.org/10.1177/0887403420911415.

16. Hannon L, Neal M, Gustafson AR. Out-of-place and inplace policing: an examination of traffic stops in racially segregated Philadelphia. Crime Delinq. 2021;67(67):868-90. https://doi.org/10.1177/0011128720926122.

17. Geller A, Fagan J, Tyler T, Link BG. Aggressive policing and the mental health of young urban men. Am J Public Health. 2014;104(12):2321-7. https://doi.org/10.2105/ AJPH.2014.302046.

18. Toro JD, Lloyd T, Buchanan KS, et al. The criminogenic and psychological effects of police stops on adolescent black and Latino boys. PNAS. 2019;116(17):8261-8. https://doi.org/10.1073/pnas.1808976116.

19. Sewell AA, Jefferson KA, Lee H. Living under surveillance: gender, psychological distress, and stop-question-and-frisk policing in New York City. Soc Sci Med. 2016;159:1-13. https://doi.org/10.1016/j.socsc imed.2016.04.024.

20. Edwards F, Lee H, Esposito M. Risk of being killed by police use of force in the United States by age, race-ethnicity, and sex. PNAS. 2019;116(34):16793-8. https://doi. org/10.1073/pnas.1821204116.

21. Sewell AA, Feldman JM, Ray R, Gilbert KL, Jefferson KA, Lee H. Illness spillovers of lethal police violence: the significance of gendered marginalization. Ethn Racial Stud. 2020; 1-26. https://doi.org/10.1080/01419870.2020. 1781913.

22. Bor J, Venkataramani AS, Williams DR, Tsai AC. Police killings and their spillover effects on the mental health of Black Americans: a population-based, quasi-experimental study. Lancet. 2018;392(10144):302-10. https://doi.org/ 10.1016/S0140-6736(18)31130-9.

23. Sewell AA. Policing the block: pandemics, systemic racism, and the blood of America. City Community. 2020;19(3):496-505. https://doi.org/10.1111/cico.12517.

24. Brooks R, Lopez C. Policing in a time of pandemic: recommendations for law enforcement. Edmond $\mathrm{J}$. Safra Center for Ethics Harvard University; 2020:1-21. Accessed March 9, 2021. https://ethics.harvard.edu/files/ center-for-ethics/files/7policingpandemic.pdf?m=15905 00595.

25. Reinhart E, Chen DL. Incarceration and its disseminations: cOVID-19 pandemic lessons from Chicago's cook county jail. Health Aff. 2020;39(8):1412-8. https://doi. org/10.1377/hlthaff.2020.00652.

26. Reinhart E, Chen DL. Carceral-community epidemiology, structural racism, and COVID-19 disparities. PNAS. 2021;118(21). https://doi.org/10.1073/pnas.2026577118.

27. Jiménez MC, Cowger TL, Simon LE, Behn M, Cassarino N, Bassett MT. Epidemiology of COVID-19 among incarcerated individuals and staff in Massachusetts jails and prisons. JAMA Netw Open. 2020;3(8): e2018851. https:// doi.org/10.1001/jamanetworkopen.2020.18851.

28. Webb Hooper M, Nápoles AM, Pérez-Stable EJ. COVID-19 and Racial/Ethnic Disparities. JAMA. 2020;323(24):2466-7. https://doi.org/10.1001/jama.2020. 8598.

29. Maynard R, Ritchie AJ. Black communities need support, not a coronavirus police state. Vice News. April 9, 2020.

30. Hodgkinson T, Andresen MA. Show me a man or a woman alone and I'll show you a saint: changes in the frequency of criminal incidents during the COVID-19 pandemic. J Crim Just. 2020;69: 101706. https://doi.org/10. 1016/j.jcrimjus.2020.101706.

31. Bernal JL, Cummins S, Gasparrini A. Interrupted time series regression for the evaluation of public health interventions: a tutorial. Int J Epidemiol. 2017;46(1):348-55. https://doi.org/10.1093/ije/dyw098.

32. Tessler H, Choi M, Kao G. The anxiety of being Asian American: hate crimes and negative biases during the COVID-19 pandemic. Am J Crim Justice. Published online June 10, 2020:1-11. https://doi.org/10.1007/ s12103-020-09541-5.

33. Francis CE. Charleston police department alternative call response plan for non-emergency calls.; 2020:1. https:// www.charleston-sc.gov/DocumentCenter/View/26172/ 
Charleston-Police-Department-Alternative-Call-Respo nse-Plan-For-Non-emergency-Calls. Accessed 1 July 2020.

34. Scott W. San Francisco Police Department Notice: Enforcement of Public Health Orders. Vol 20-045.; 2020. https://www.sanfranciscopolice.org/sites/default/files/ 2020-03/SFPDNotice20.045.20200323.pdf. Accessed 1 July 2020.

35. Dholakia N, Rahman I, Stagoff-Belfort A. Four ways the pandemic made us rethink our criminal legal system. Vera Institute of Justice. Accessed June 11, 2021. https://www. vera.org/blog/four-ways-the-pandemic-made-us-rethinkour-criminal-legal-system.

36. NCSC. Coronavirus and the courts. Published February 25, 2021. Accessed March 9, 2021. https://www.ncsc.org/ newsroom/public-health-emergency.

37. Advancing Public Health Interventions to Address the Harms of the Carceral System. American Public Health
Association; 2020. https://www.apha.org/policies-andadvocacy/public-health-policy-statements/policy-datab ase/2021/01/14/advancing-public-health-interventionsto-address-the-harms-of-the-carceral-system. Accessed 1 July 2020.

38. Emmer P, Ervin W, Purnell D, Ritchie AJ, Wang T. Unmasked: impacts of pandemic policing. Community Resource Hub for Safety \& Accountability; 2020:1-107. Accessed March 9, 2021. https://communityresourcehub. org/resources/unmasked-impacts-of-pandemic-policing/.

Publisher's Note Springer Nature remains neutral with regard to jurisdictional claims in published maps and institutional affiliations. 